\title{
Increasing Diversity in the Marine Sciences Through the Minorities in Marine Science Undergraduate Program
}

\author{
Brian L. Bingham \\ Western Washington University, brian.bingham@wwu.edu \\ Stephen D. Sulkin \\ Western Washington University, Stephen.Sulkin@wwu.edu \\ Suzanne L. Strom \\ Western Washington University, Suzanne.Strom@wwu.edu \\ Gisèle Muller-Parker \\ Shannon Point Marine Center
}

Follow this and additional works at: https://cedar.wwu.edu/esci_facpubs

Part of the Bilingual, Multilingual, and Multicultural Education Commons, and the Marine Biology Commons

\section{Recommended Citation}

Bingham, Brian L.; Sulkin, Stephen D.; Strom, Suzanne L.; and Muller-Parker, Gisèle, "Increasing Diversity in the Marine Sciences Through the Minorities in Marine Science Undergraduate Program" (2003). Environmental Sciences Faculty and Staff Publications. 36. https://cedar.wwu.edu/esci_facpubs/36 


\section{Increasing Diversity in the Marine Sciences Through the Minorities in Marine Science Undergraduate Program}

\author{
Brian L. Bingham \\ Stephen D. Sulkin \\ Suzanne S. Strom \\ Gisèle Muller-Parker
}

\author{
Department of Environmental Sciences, Western Washington, University, \\ Bellingham, WA 98225-9079 \\ Shannon Point Marine Center, Western Washington, University, Anacortes, WA \\ 98221 \\ Shannon Point Marine Center, Western Washington University, Anacortes, WA \\ 98221
}

Biology Department, Western Washington University, Bellingham, WA 98225-9160

\begin{abstract}
The Minorities in Marine Science Undergraduate Program (MIMSUP) is an academic program at Western Washington University's Shannon Point Marine Center (SPMC) that seeks to increase the representation of minority individuals in the marine sciences. For the past 13 years, groups of students have spent two 10-week quarters at SPMC studying marine science, doing independent research, and developing the skills needed for success as marine scientists/educators. Program elements include formal coursework in marine science, supervised independent research, training in up-to-date field and laboratory investigative techniques, experience developing scientific and personal job-related skills, and introduction to the career options open to marine scientists. Results indicate that the program is impacting the career paths of student participants; program alumni seek advanced education and pursue careers in the marine and environmental sciences. MIMSUP introduces underrepresented students to the marine sciences, helps them develop greater confidence in their potential, and prepares them for successful careers in this field.
\end{abstract}

Keywords: under-represented, minority, diversity, outreach education

\section{INTRODUCTION}

The Minorities in Marine Science Undergraduate Program (MIMSUP), funded by the National Science Foundation, was initiated at Western Washington University's Shannon Point Marine Center in 1991. MIMSUP was developed to address the reported under-representation of ethnic/racial minority groups in marine science disciplines (National Science Board, 1989). Relatively few minority students traditionally seek careers in oceanography or marine science (Olson, 1999) and an extremely low number of Ph.D. degrees in these fields are earned by minorities (National Science Foundation, 2000). This problem persists despite strong marine science programs at several minority-serving institutions, focused specialty programs for minority students, and a growing number of minority undergraduates earning degrees in the aquatic sciences (Gilligan 1996).

Recruitment and retention of minority students are critical to maintaining and enhancing the intellectual health of marine science disciplines. A continuing low level of enrollment of minority students in marine science graduate programs has significant implications for the profession. Indeed, two National Science Foundation-sponsored workshops have concluded that the near absence of minorities in the ocean sciences is a priority issue that must be addressed (Seitz, 1992; McManus et al., 2000). Demographic changes in the U.S. are producing ever-growing minority populations; projections indicate that minorities will constitute half the U.S. population by mid-century (Day, 1996; Lollock 2001). Much of this growth will occur in coastal regions where important management decisions will be made. Effective management of these areas and their resources will require trained experts who can connect with the local populations - connections that will be strongest if scientists and managers "look like the populations they serve" (Cuker 2001).

Minority students interested in the natural sciences often choose health-related fields. While this is obviously an appropriate path for some, others simply have not been introduced to alternative careers, including the marine sciences. Here we provide data on MIMSUP including a description of the program structure, its development, and the program outcomes. Our hope is that others interested in recruiting and training under-represented minority students in the geosciences will benefit from our experiences.

\section{PROGRAM AND STUDENT ACHIEVEMENT}

The ultimate value of any program lies in its record of accomplishment and its ability to demonstrate that record. An important element of MIMSUP is an intensive outcomes assessment (described later in more detail) that 1) permits rigorous internal analysis leading to periodic revision of program elements and 2) provides a database of student accomplishment. To permit assessment of program success and, therefore, validate its use as a model, we provide the following data on program and individual student achievement.

Between 1991 and 2003, 103 students from ethnic/racial groups underrepresented in marine science participated in MIMSUP (Figure 1). One hundred and one of those completed the program; 100 of the 103 have either completed or are currently completing their baccalaureate degrees. Of the 78 students who have completed their undergraduate degrees, two have gone on to complete doctoral programs; both of these are currently NIH Post-doctoral Fellows. Seven alumni are currently in doctoral programs ( 3 of these also completed Master's degrees). Four have completed professional degrees; five others are currently in professional degree programs. Sixteen students have completed Master's degrees, 17 are in Master's degree programs, and at least 4 others are currently applying for graduate admission. 


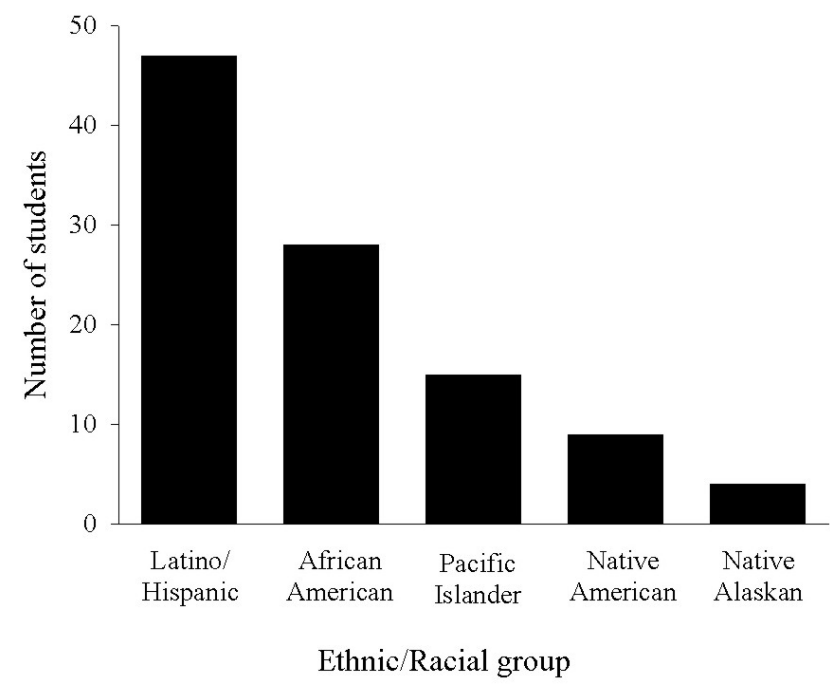

Figure 1. Race/ethnicity of 103 participants in the Minorities in Marine Science Undergraduate Program (1991-2003).

Most of our graduates have entered marine or related environmental professions. Figure 2 summarizes the current status of all students who have completed baccalaureate degrees (including those in graduate school). Fifty-one of these 78 alumni (65\%) are working in marine science, biology or related environmental fields. Of the nine students who have completed or are currently pursuing Ph.D. degrees, seven are in marine fields. The other two are in molecular biology and environmental science.

Student participants have earned a remarkable number of scholarships, internships and other awards during and subsequent to their MIMSUP experience (Table 1). In evaluating this record of student accomplishment, it is important to note that while some of these students were well-accomplished academically upon entering the program, the group overall is representative of the average undergraduate pool of students in the United States. As one measure of their status, the average entering GPA was 3.0. Program evaluations submitted by the students one year after the program indicate that MIMSUP informed them of opportunities, helped them develop skills, and gave them confidence to pursue their goals. In addition, participation in MIMSUP boosted their subsequent academic work; student GPAs at the home institutions generally improved after the program. With no comparison group, it is impossible to attribute higher GPA's directly to participation in MIMSUP. However, $84 \%$ of our program alumni in surveys taken one year after the program stated that participation in MIMSUP helped them do better academically the following year (3\% said MIMSUP did not help; $13 \%$ said they did not know if it helped).

\section{ACADEMIC PROGRAM}

The MIMSUP curriculum, which includes two 10-week quarters of intensive marine science study, is presented to eight students we recruit annually from undergraduate institutions around the nation. The students spend the Winter and Spring Quarters at SPMC taking marine science courses, being trained in

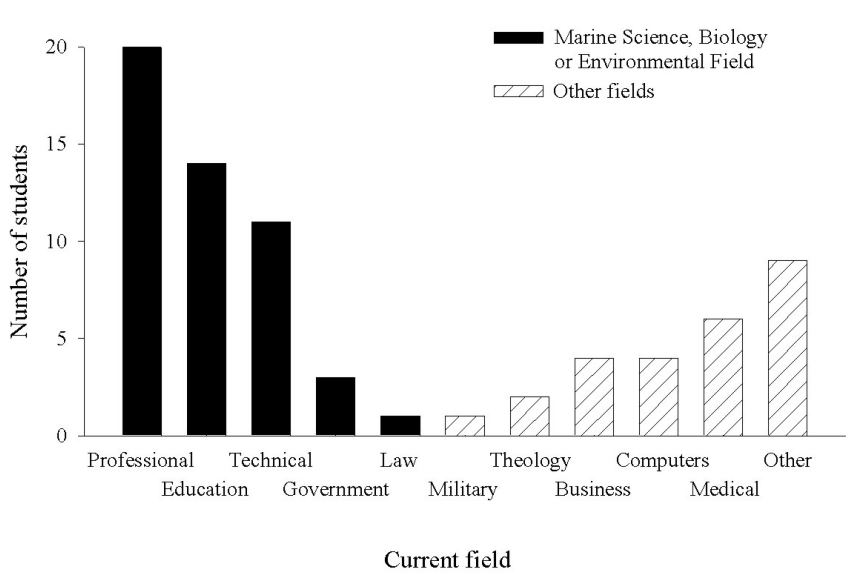

Figure 2. Current (2003) status of MIMSUP alumni. These represent only the 78 alumni who have completed a B.S. or B.A. degree. The "Professional" category includes program alumni in post-doctoral positions or pursuing science graduate degrees. "Education" includes 2 students pursuing M.Ed. degrees; the remaining 14 individuals are working in public aquaria, science centers, or are actively teaching (institutions range from grade schools to 4-year colleges). "Technical" includes individuals working as research assistants, consultants or science technicians. "Government" employees are in such agencies as the Department of Environmental Regulation and the Environmental Protection Agency. The alumna in the law category is an environmental lawyer. The "Other" category includes at-home parents, law enforcement officials, and retail workers.

laboratory and field methods, and carrying out independent research.

Most incoming program participants have limited experience in the marine sciences, in working intensively in the relatively informal environment of a marine laboratory, and in the methodology of research. Furthermore, the students typically represent a wide range of backgrounds, cultures, and academic experiences. We have learned the value of developing a sense of community among the students, faculty and staff who will be working together. Daily mentoring and individual tutoring are critical to establishing an atmosphere of accomplishment and trust that sustains the students throughout the 5-month program. This is a theme that runs through the entire experience.

Initial Orientation - The first two weeks of MIMSUP are a particularly important period for the students; they must gain confidence in their own abilities, become comfortable with the support structure we provide, and understand the level of commitment we expect. Key to accomplishing this program goal is frequent formal and informal contact between the MIMSUP students and the SPMC faculty, staff and graduate students. Activities during this orientation period generally include an initial welcome and lab tour, safety orientation and training by SPMC staff, an afternoon of ship-board dredging/ sampling, two day-long field trips with the MIMSUP director, one-on-one interviews between students and potential research advisers, a laboratory potluck, and 


\begin{tabular}{|c|c|c|}
\hline & During MIMSUP & After MIMSUP \\
\hline Presentation at scientific conferences & 83 & $51(20)$ \\
\hline Best student paper awards & 6 & $6(4)$ \\
\hline Refereed publications & N/A & $35(10)$ \\
\hline Internships & N/A & 107 \\
\hline Fellowships/scholarships & N/A & 40 \\
\hline Research grants & N/A & 7 \\
\hline
\end{tabular}

Table 1. Accomplishments of students while participating in MIMSUP and after completing the program. Numbers in parentheses represent presentations and publications by students after leaving MIMSUP, but resulting directly from research completed as part of the program. These results are for 103 student participants between 1991 and 2003.

outreach training with our outreach coordinator (described below). Meeting with staff and faculty early in the program demonstrates our commitment to the students and their success and quickly puts in place the basic support network on which the students will rely.

Winter Quarter Curriculum - During the Winter Quarter, students complete 16 credits (equivalent to 10 semester credits). The curriculum includes a 6-credit laboratory/field course in Oceanography, a 5-credit Current Trends in Marine Science course, and a 5-credit Independent Research course. While highlighting marine science, the curriculum focuses on fundamental skills (e.g., writing, critical thinking, quantitative analysis, research techniques) so that even a student who ultimately decides not to pursue a career in the sciences will benefit from the time spent in the program.

Oceanography - This course gives students an intensive introduction to the breadth of topics that constitute oceanography while providing a common knowledge base for the upper division Spring Quarter courses. The small class size (8 students) and full-time attention of an instructor allow us to effectively address the variety of academic backgrounds represented in each student group.

Because we have considerable flexibility in use of time and space in the Winter Quarter, and because the class includes only the 8 MIMSUP participants, we are able to use innovative instructional approaches that incorporate writing, discussion, synthesis and group work. The laboratory sessions, for example, incorporate group jigsaw exercises, where students work in pairs to learn a subset of the material ahead of time, then combine into groups of "experts" to solve problems and interpret data during the laboratory meeting (Tewksbury, 1995). The goal is to present the spectrum of skills needed to ask and answer questions in science, with an emphasis on the need to teach and learn from one's scientific peers.

Current Trends in Marine Science - In this course, we familiarize students with the local marine environments and introduce the tools used to study those environments. We also teach them about basic research methodology, current issues in the field, and career tracks open to marine scientists.

In weekly workshops, students gain hands-on experience using advanced instruments and technology. Workshops incorporate computerized data acquisition and are regularly updated to include the most current technology. We articulate workshops with research seminars and weekly literature discussion sessions emphasizing current research themes and critical analysis.

One of our workshops, while not focused on instrumentation or technology, is extremely important to the students' future success. Shortly after their arrival, the students meet with a career placement professional who instructs them on resumes and curriculum vitae, interview skills, professional letter writing, and graduate school applications. The students subsequently apply these skills in applying for summer internships, fellowships and graduate school positions (activities we strongly encourage through the Winter Quarter; see Table 1).

In teaching these skills, we emphasize graduate school and application strategies. Feedback from the students indicates that this information is extremely useful in 1) getting them to think about graduate school and 2) helping them know how to apply. Graduate students also work side by side with the MIMSUP students during the program. They take courses together, interact through research activities, and live in the same housing unit. This provides frequent opportunities to informally discuss graduate school. In this way, MIMSUP participants learn why students pursue graduate degrees, what their programs involve, and how they can best prepare themselves to do the same thing. We have recently expanded this effort by bringing in MIMSUP alumni to interact with the students for several days. These "near-peers" (typically post-docs or Ph.D. candidates) are able to talk with the students and share graduate school experiences.

Based on our assessment of student performance during the first three years of MIMSUP, we incorporated formal weekly math and writing instruction in the Current Trends course. This "directed tutoring" approach allows us to address weaknesses in individual student's backgrounds, while helping the students prepare for the Spring Quarter courses, the GRE and graduate school.

Many MIMSUP students, though interested in marine science, have no clear idea how it can become a career. We strive to provide a balanced perspective on job opportunities with weekly hosted visits to government agencies (e.g., NOAA, Washington Department of Fish and Wildlife), private industries (e.g., consulting companies, hatcheries), non-governmental organizations, public aquaria, and academic institutions (K-12, community colleges and universities). 
Directed Individual Research - This course is designed to provide each student with the experience of conducting an individual, supervised research project, modeled after a beginning graduate experience. During the initial orientation period, the students receive a list of potential mentors drawn from Western Washington University faculty and visiting researchers at the marine center. Over the following week, the students independently meet with and interview these individuals, discussing their mutual interests and potential for collaboration. Each adviser is then matched up with a single student, maximizing the time for quality mentoring. The experience gives the students a unique perspective on the process of identifying, meeting, and finding a place in the laboratory of a graduate adviser.

Students and their advisers plan and undertake a supervised project. Periodic oral updates to the class ensure that each student is making progress toward his/her research goal. Direct, frequent interaction between the student and the adviser is critical to the success of the research experience. This requires a substantial commitment by the faculty.

The MIMSUP director administers the research course, working closely with the both students and the advisers. Grading is based on written reports, oral reports, the research notebook, and an adviser's evaluation.

There are significant challenges to conducting an effective research course of this type, including the short time period available ( 1 quarter), the competing demands of other courses, and the limitations imposed by carrying out the research during the winter. Nevertheless, the experience is extremely valuable and has contributed to many important student accomplishments including poster and oral presentations, publications, and senior thesis projects carried out by students upon their return to their home institutions (Table 1). To ensure that there is adequate time to complete the work, the entire "research experience" is spread over both quarters of the program. The actual research is completed in the winter quarter (i.e., in the Directed Independent Research course); the "communication" aspects of research (e.g., analyzing data, preparing manuscripts, creating posters and giving talks) are addressed during the spring quarter in the Scientific Communications course (see below).

Spring Quarter Curriculum - The Spring Quarter curriculum includes a Scientific Communication course designed specifically for the MIMSUP participants and two additional courses offered annually as part of the Shannon Point Marine Center spring program for Western Washington University students. Thus, there is a transition from a program in which the MIMSUP students form a cohort with a strong group dynamic and focused faculty attention (Winter Quarter) to a program in which they are integrated into a broader student population.

Scientific Communication - The Scientific Communications course builds on the writing tutorials offered Winter Quarter by providing instruction on various forms of communication. Students use the results of their Winter Quarter research as the basis for developing written, oral and poster versions of final reports. The written report, in the format of a refereed journal, includes multi- ple drafts reviewed by the adviser and the course instructor. Final manuscripts are subjected to peer review with the students serving both as authors and anonymous reviewers. The manuscripts are revised to address reviewers' comments and resubmitted as final copy. This exercise demystifies the publication process and helps teach the students to critically review their own work and that of others.

The instructor for the Scientific Communications course is the MIMSUP director who also administers the Winter Quarter Independent Research course. This permits a seamless integration of the actual research and the scientific writing. In this way, the students experience the entire research experience from planning through data analysis to final presentation. The research advisers are heavily involved throughout the process, advising the research, assisting with data analysis, reviewing preliminary drafts and attending presentations. This partnership helps ensure a successful research experience for the students and their advisers.

In addition to preparing their research results as a journal article, the students create posters for a scientific meeting. Near the end of the program, they present these at a research conference on the main campus. The students also give oral presentations at a final symposium modeled after a session at a scientific meeting. Those presentations are videotaped and formally evaluated with the course instructor.

As the culmination of this course and their research, the students present their work at a national conference, usually at a meeting of the American Society of Limnology and Oceanography (ASLO). This has been possible through the ASLO/Hampton University "Minorities in the Aquatic Sciences" project that funds students from underrepresented groups to attend the annual meeting. This capstone event is an excellent opportunity for the students to present their research and to practice the skills they have developed over the previous 2 quarters in the context of a major scientific meeting. When presentation at ASLO has not been possible, the students have presented their work at meetings of the Estuarine Research Federation (ERF) or the Pacific Estuarine Research Society (PERS).

Other Courses - In addition to the Scientific Communication course, the Spring Quarter curriculum includes 2 additional upper division courses (10 credits). These are selected from courses provided as part of the general Spring Quarter program at SPMC (e.g., Marine Ecology, Marine Invertebrates, Algae, Marine Toxicology, Aquatic Ecosystems Management, Fisheries Management). Spring Quarter courses are laboratory and field intensive with strong hands-on training and additional independent research components.

Outreach Program - In 1994, a work-study component was added to MIMSUP in response to suggestions from previous participants. While the MIMSUP budget provides essential support for travel, tuition, and housing, many students give up jobs or other site-based forms of financial support at their home institutions to participate. The work-study program, which takes place primarily during the Winter Quarter, was instituted to provide modest support to help cover incidental costs.

The work-study program is designed to provide an additional type of educational opportunity for the students. Recognizing 1) the value of diversifying the students' academic skills to compete in the job market 
and 2) the strong desire on the part of the K-12 education system to enhance classroom science instruction, we developed a partnership with the local school district. This partnership involves MIMSUP students visiting local elementary school classrooms to present marine science lessons. The MIMSUP students are paid for the time they spend in preparation and for actual contact hours.

As with most components of MIMSUP, the outreach program has evolved since its inception as we have learned from the students and the local school teachers how to maximize the value of this program for both. Organization, proper training, and appropriate lesson plans tailored to target audiences are key ingredients. Beginning in 1997, we added a part-time Outreach Coordinator, whose responsibilities cover these issues, to the staff. Prior to the start of Winter Quarter, the Outreach Coordinator selects target grades (typically $2^{\text {nd }}$ and $4^{\text {th }}$ ) and schedules the weekly classroom visits with the school system through the Winter Quarter. The MIMSUP students are organized into 2 outreach teams (4 students per team) and each classroom receives two consecutive weekly visits. This allows for follow-up activities and gives the school children an opportunity to see their MIMSUP instructors a second time (an approach strongly recommended by the teachers). The Outreach Coordinator presents several training sessions during the first two weeks of the Winter Quarter to prepare the MIMSUP students for the classroom. The training includes both preparation on the substance of the lesson plans (tidal zones, shore habitat, plankton) and instruction on teaching techniques for the target grades. At the conclusion of the Winter Quarter, a formal evaluation process solicits information from the MIMSUP students and the school teachers with a summary report prepared by the Outreach Coordinator.

In addition to teaching marine science, MIMSUP participants also use their time in the classroom to share their cultural heritages with the school children, a valuable experience for both groups. Evaluations from the K-12 students and teachers and from the MIMSUP participants have been overwhelmingly positive. Several summer internships obtained by MIMSUP students and some subsequent career decisions can be traced to this experience. The outreach gives the students important experience while contributing to science education in the local grade schools. Such quality outreach efforts have been strongly endorsed by the National Science Foundation Center for Ocean Sciences Education Excellence (COSEE) workshop (McManus et al., 2000).

\section{ADMINISTRATIVE SUPPORT}

Administrative support for MIMSUP has been strong since the program was first conceived. Increasing diversity in programs and staff is a strategic principle at Western Washington University. Furthermore, the university is committed to providing experiential learning opportunities. The Shannon Point Marine Center has been at the forefront of providing to undergraduates the most up-to-date training in field and laboratory investigative techniques. Therefore, the concept of MIMSUP fits well with both University and SPMC missions.

From the beginning, it was clear that, to be successful, the program would require intensive faculty involvement at a level that could only be assured with a dedicated position assigned to the program. Accordingly, the University, through the Provost's office, allocated a new faculty position whose primary task is to manage the program and serve as its chief academic administrator. This was achieved before the initial MIMSUP grant application was submitted to the National Science Foundation.

Administering the program also requires close coordination with other activities at the marine center. The SPMC Director identifies MIMSUP as a principal activity for the marine center during the Winter Quarter, assigning laboratory space, boat time, and support staff needed to carry out program activities. Identifying program participation as an expected duty of faculty and visiting scientists at SPMC assures adequate supervision of the research projects and focused support for the MIMSUP students.

\section{STUDENT RECRUITMENT AND ENROLLMENT}

Recruitment - Despite our record of program success and the efforts of an enthusiastic group of MIMSUP alumni, recruitment of applicants remains a significant challenge. Applicants must be willing to interrupt their on-going academic programs for more than five months (in the middle of the academic year), receive approval from their home institutions for transfer of credit, leave behind jobs and a variety of support structures, and move to an area where the climate and culture are likely quite different.

We use a variety of recruiting methods to reach potential applicants. Each year we distribute a flyer to colleagues and to biology and environmental science departments at minority serving institutions and other colleges and universities around the country. While it is hard to assess the effectiveness of these flyers in directly attracting students, they do keep the program visible to faculty advisers who may bring it to the attention of prospective students. We maintain a program webpage (http://www.wwu.edu/ mimsup) and distribute announcements on several internet newsgroups. We have worked to establish contacts in the American Indian Science and Engineering Society (AISES) and the Society for Advancement of Chicanos and Native Americans in Science (SACNAS) and have also advertised through these organizations.

Ultimately, however, the most successful recruiting tool has been the network of personal contacts the program faculty have established over the years. Professional colleagues recommend potential applicants to us and serve as intermediaries in establishing personal contact. Advisers of former students, who have seen the value of the program firsthand, serve as a source of students, as do our MIMSUP alumni. In this way, we identify potential applicants with whom we can work to ensure they have the necessary course background to apply. The growth of internet tools has facilitated and streamlined applications. However, reaching the broad audience of potential applicants continues to be a challenge.

Selection - The intended audience for MIMSUP is students majoring in biology or environmental science who are open to marine science as a career track. In general, at least junior standing is required to have completed the introductory courses in biology, chemistry and mathematics that are prerequisite for 
some of the Spring Quarter courses. However, because of the small size of our student group and the focus on individual success, we can use considerable flexibility in considering applicants; we have accepted promising sophomore as well as senior-level students with majors ranging from chemistry and math to education and liberal studies. Grade point averages are considered in selecting applicants. However, we again allow considerable latitude. Over the years, we have accepted a number of students who had not yet been in an environment that allowed them to fully express their abilities. Ultimately, the statement of interest and the faculty letter of recommendation are the best indicators that a student will do well and benefit from the program.

Funding from the National Science Foundation supports all 8 MIMSUP students. The funding covers tuition and fees for two quarters, housing costs, travel to the Shannon Point Marine Center and the outreach work-study program.

Preparing Participants for the Program - Students participating in MIMSUP leave their home institutions for 2 full quarters. To help students prepare logistically for this, we inform them of their selection by mid-November of each year. The MIMSUP director calls each student personally. Experience has shown that this is much better than a simple acceptance letter. A phone call allows us to directly address concerns the students (and parents) often have and sets a tone of accessibility and support for the students and their families.

Within a week, we provide a packet of information detailing the structure of the program and the content of the courses the students will complete. We then work with the students and their home institutions to determine which credits will transfer and how courses completed during MIMSUP can substitute for courses required for the student's major. Ideally, students should return to their home institutions with 31 quarter credits (equal to 20 semester credits), but this is rarely the case. There are enormous institution-to-institution and program-to-program differences in credit transfers. While some MIMSUP students have returned to their home institutions with the full complement of 31 credits, others are able to transfer fewer (as few as 10 on several occasions). Furthermore, participation in MIMSUP occasionally interrupts a course sequence at the home institution. Consequently, some students have had to delay graduation to participate in the program. These are issues we work to clarify prior to a student's participation in MIMSUP.

The other aspect of coordination with the home institution that must be handled early is the transfer of financial aid. Some students choose to transfer financial aid to help cover their personal expenses while at SPMC. This is accomplished through an agreement between Western Washington University and the student's home institution. We have developed a consortium agreement that is sent to each student immediately upon acceptance into the program. The student must work with the home institution to make necessary arrangements before coming to SPMC. This requires considerable communication among the student, the MIMSUP director, and the financial aid officers at WWU and the home institution.

In addition to preparing logistics for student participants, we spend time preparing the students themselves for MIMSUP. Program participants come from a variety of locations and circumstances (ranging from large universities in major metropolitan areas to small minority serving institutions in residential communities). Moving to northwest Washington State generally entails a major change in environment and culture for them. Spending five months at a field laboratory in a small town can be challenging.

We begin to address this issue immediately after students are accepted. With their acceptance letter, we send brochures and information about the town of Anacortes. We emphasize that they will be at a field site with limited access to town or the university. Working with previous program participants, we have written up a description to help the newly accepted students understand the circumstances in which they will be studying. This kind of information is important in helping the students prepare for the transition to their new surroundings.

A recurrent theme from program alumni is the desire for additional social interaction while at the marine center. Unfortunately, this is not an issue we can completely address given the nature of a field laboratory. Over the years, some students have gotten involved in the local community through cultural, sports or church groups. Resident undergraduate and graduate students have provided important connections to other activities. Our most effective effort to address this issue, however, has been through the hiring of a resident graduate assistant who lives with the students, keeps them informed of activities, and helps make arrangements for them to participate in activities on the main university campus. This graduate assistant is partially funded through the National Science Foundation award.

\section{PROGRAM EVALUATION AND ASSESSMENT}

The structure of MIMSUP has evolved over the past decade in response to student feedback and to our own changing perceptions of the best way to help our students. A thorough continuing assessment of all components of MIMSUP is an essential element of the program and has contributed enormously to its success. Evaluations have led to significant programmatic revisions as well as adjustments in the schedule and support structure of the program. Assessment is more than an evaluation exercise that describes outcomes; it is a feedback mechanism we use to improve the program by testing and implementing new approaches.

Shortly after the students complete the program and leave the marine center, the MIMSUP faculty and staff meet to evaluate the need for possible changes in the upcoming program based on their own perceptions and those provided by the students. Two months later, the students are invited to formally comment on the program by submitting a formal evaluation. After two months, the MIMSUP experience is still fresh in students' minds, but they have had the chance to consider it from a more distant perspective. A second evaluation is solicited one year later to determine how students perceive the experience after having spent a full academic year back at their home institution. This approach provides quantitative and qualitative data to help us evaluate how MIMSUP has affected each student's subsequent academic performance and his/her career path.

For the first 9 years of the program, we solicited these evaluations through the mail. Returns averaged $60 \%$ for the 2 -month evaluations and $42 \%$ for the 1 -year evalua- 
tions. In 2000, we moved to a web-based survey form (visit http://www.wwu.edu/ mimsup/sampleevaluation.html to see a sample form). Returns jumped to $89 \%$ and $75 \%$ for the 2-month and 1-year surveys, respectively.

Supplementing these summative evaluations, and perhaps even more useful, is a considerable effort to solicit informal formative evaluation from both MIMSUP students and staff. During the program, students are frequently involved in discussion of program elements to identify and correct problem areas. The staff meet regularly to discuss and resolve problems, involving both individual students and general program issues. At the end of the program, students are invited to meet collectively with the program staff to discuss the program's strengths and weaknesses, the benefits they derived from the experience, their future plans and any suggestions they have for improvement. Although the small size and intimate nature of the program make formal anonymous assessment virtually impossible, students can discuss the program with either the SPMC director or the MIMSUP director in a private and confidential manner if they choose to do so.

Perhaps the most important evaluation element involves our continued, frequent communication with the students themselves. MIMSUP alumni have kept close contact with us, informing us of their plans and accomplishments and seeking advice or letters of reference. The MIMSUP director makes special efforts to track our MIMSUP alumni and encourage their continued communication with us and with other MIMSUP participants. Success in this effort is shown by the data in Table 1 and Figure 2. The close bond that exists among MIMSUP students is another measure of the success of the program.

\section{CONCLUSIONS}

Successfully administering MIMSUP requires a substantial institutional commitment of personnel and facilities. The most obvious elements are faculty and staff time, facilities resources, and access for the students to university courses. Even more important, however, is a commitment on the part of individual faculty to spend the time necessary to effectively mentor the students. All of this implies a commitment in principle on the part of the institution's administration. A program of this nature could not function without that support.

MIMSUP has been a very successful effort to increase minority participation in the marine sciences. Many of our program alumni are pursuing advanced education and are finding careers in the field. Coordination with other minority aquatic science programs (e.g., the NOAA diversity program, the Savannah State University/Harbor Branch Bridge to Research in the Marine Sciences program, the ASLO/Hampton University program) has helped enormously in this effort. Together, these institutions and programs are creating a network that supports these students on their way to professional and academic careers in the sciences.

When asked to identify the single most important feature of MIMSUP, students give a variety of responses. However, some major themes emerge from their comments. Most students identify skills acquisition as the most valuable thing they learn. This includes computer skills, research skills, writing and public speaking skills. They also place a high value on the relationships they build with other students, faculty and professionals in the field. Both of these areas contribute to a feature we perceive as the greatest benefit of the program: students gain a good sense of their own abilities, greater confidence in their potential, and the motivation to pursue their goals. It is satisfying to see our former students now emerging as the scientists, teachers, policy makers, leaders and mentors who will carry this important effort forward.

\section{ACKNOWLEDGMENTS}

We gratefully acknowledge National Science Foundation funding for the Minorities in Marine Science Undergraduate Program (Grants \#OCE-9016292, OCE-9315422 and OCE 9729316). We thank the many faculty, staff and administrators at Western Washington University who have enthusiastically supported MIMSUP. Support staff at the Shannon Point Marine Center have been instrumental in working with the students and assisting with program administration. We also express gratitude to the many individuals from other universities, community colleges, government agencies and private enterprises who have worked with our students, sharing their own knowledge of the marine sciences and encouraging our students to succeed.

\section{REFERENCES}

Cuker, B., 2001, Steps to increasing minority participation in the aquatic sciences: catching up with shifting demographies, American Society of Limnology and Oceanography Bulletin, v. 10, p. 17-21.

Day, J.C., 1996, Population projections of the United States by age, sex, race, and Hispanic origin: 1995-2050, Current Population Reports. U.S. Census Bureau, Arlington, VA.

Gilligan, M.R., 1996, Promoting diversity in the fisheries profession: the role of historically black colleges and universities, Fisheries, v. 21, p. 26-29.

Lollock, L., 2001, The foreign born population in the United States, Current Population Reports, U.S. Census Bureau, Arlington, VA.

McManus, D.A., Walker, S.H., Cuker, B.E., Goodnight, P., Humphris, S., Kenner-Chavis, P., Reed, D., Robigou, V., and Schubel, J.R., 2000, Center for ocean science education excellence (COSEE), The report of a workshop sponsored by the National Science Foundation.

National Science Board, 1989, Science and Engineering Indicators - 1989, National Science Board, U.S. Government Printing Office, Washington, D.C. NSB 89-1

National Science Foundation, 2000, Women, Minorities, and Persons with Disabilities in Science and Engineering, 2000, NSF 00-327, Arlington, VA.

Olson, K., 1999, Despite increases, women and minorities still underrepresented in undergraduate and graduate S\&E education, NSF 99320, U.S. National Science Foundation.

Seitz, W., 1992, Undergraduate Programs in Ocean Sciences., Workshop Report, Galveston, Texas, 1992, Joint Oceanographic Institutions, Inc., Washington, D.C., 77 p.

Tewksbury, B.J., 1995, Specific strategies for using the "jigsaw" technique for working in groups in non-lecture-based courses, Journal of Geoscience Education, v. 43, p. 322-326. 